\title{
RESPONSABILIDAD DEL ESTADO POR SIMPLE CAMBIO DE JURISPRUDENCIA EN EL DERECHO COLOMBIANO*
}

\author{
AJANI AKIN CUESTA DAVU $*$ \\ Presentado: 18 de abril de 2016 - Aprobado: 13 de septiembre de 2016 \\ 10.24142/raju.v11n23a2
}

\section{Resumen}

Este artículo analiza si el simple cambio de la jurisprudencia puede generar la responsabilidad patrimonial del Estado en el derecho colombiano. Con ese propósito se presentará cómo en la práctica judicial el Consejo de Estado y la Corte Suprema de Justicia modifican su jurisprudencia, y el efecto que ello genera para las partes en litigio. Posteriormente, serán descritos los elementos que estructuran la responsabilidad del Estado por la actividad de la Administración de Justicia en Colombia, concretamente por error jurisdiccional. Se observa que en determinadas hipótesis es posible concluir, teóricamente, que

Artículo basado en la investigación realizada por el autor entre los años 2006 y 2007, como tesis de Maestría en Derecho - Programa en Derecho Procesal de la Universidad Externado de Colombia, denominada "Responsabilidad del Estado por aplicación retroactiva de cambios de jurisprudencia", a partir de un análisis de la jurisprudencia del Consejo de Estado colombiano. La investigación que dio lugar al artículo se efectuó entre los meses de junio y diciembre del año 2014, y analiza, ya no la responsabilidad que podría derivarse para el Estado de la aplicación retroactiva de cambios jurisprudenciales, sino, si tal responsabilidad tiene lugar por el simple cambio de jurisprudencia. La misma fue financiada por la Universidad Autónoma Latinoamericana de la ciudad de Medellín en el seno del grupo de investigación Ratio Juris, en la que el autor fue investigador principal. En la labor de rastreo jurisprudencial participaron los estudiantes Luis Gregorio Moreno Mosquera y Daniela Cataño Bedoya.

** Abogado de la Universidad Autónoma de Colombia en Bogotá, Especialista en Derecho Administrativo y Magíster en Derecho, Programa en Derecho Procesal de la Universidad Externado de Colombia. Profesor de tiempo completo de la Universidad Autónoma Latinoamericana (UNAULA) de Medellín. Correo electrónico: ajani.cuesta@unaula.edu.co 
se genera la responsabilidad del Estado en el derecho colombiano por los simples cambios jurisprudenciales.

Palabras clave: jurisprudencia, cambio de jurisprudencia, responsabilidad del Estado, daño antijurídico, error jurisdiccional.

\section{STATE RESPONSIBILITY FOR SIMPLE CHANGE OF JURISPRUDENCE IN THE COLOMBIAN LAW}

\section{Abstract}

This article analyzes if the simple change of jurisprudence can generate responsibility of the State in Colombian law. For this purpose, will be presented how in the judicial practice the Council of State and the Supreme Court of Justice changed its jurisprudence, and the effect that it generates for litigants. Subsequently they are described the elements that structure the responsibility of the State for the activity of the administration of justice in Colombia, specifically for jurisdictional error. It is noted that in certain hypothesis is possible to conclude theoretically that State responsibility is generated in the Colombian law by simple jurisprudential changes.

Keywords: case law, change of jurisprudence, state responsibility, unlawful damage, jurisdictional error.

\section{RESPONSABILITÉ DE L'ÉTAT POUR SIMPLE CHANGEMENT DE JURISPRUDENCE DANS LE DROITI COLOMBIEN}

\section{Résumé}

Cet article analyse si le simple changement de la jurisprudence peut générer la responsabilité patrimoniale de l'État dans le droit colom- 
bien. À cet effet, sera présenté comment dans la pratique judiciaire le Conseil d'Etat et la Cour Suprême de Justice ont changé sa jurisprudence, et l'effet que cela génère pour les parties en litige. Par la suite, seront décrits les éléments qui structurent la responsabilité de l'Etat pour l'activité de l'Administration de Justice en Colombie, en particulier pour une erreur juridictionnelle. Il est à noter que, dans certaines hypothèses est possible de conclure, théoriquement, que la responsabilité des Etats est généré dans le droit colombien par des simples changements jurisprudentiels.

Mots-clés : jurisprudence, changement de la jurisprudence, la responsabilité de l'État, dommages illégaux, erreur juridictionnelle.

\section{RESPONSABILITÀ DELLO STATO PER IL SEMPLICE CAMBIAMENTO DI GIURISPRUDENZA NEL DIRITTO COLOMBIANO}

\section{Riassunto}

Questo articolo analizza se il semplice cambiamento della giurisprudenza può generare la responsabilità patrimoniale dello stato nel diritto colombiano. A questo scopo saranno presentati come nella pratica giudiziaria del Consiglio di Stato e la Corte Suprema di Giustizia cambianno sua giurisprudenza e l'effetto che questo produce per le parti in controversia. Successivamente saranno descritti i loro elementi che strutturano la responsabilità dello Stato per l'attività dell'Amministrazione di Giustizia in Colombia, in particolare di errore giurisdizionale. Si osserva che in alcune ipotesi è possibile concludere, teoricamente, che se genera la responsabilità dello Stato nel diritto colombiano per quelle semplici modifiche giurisprudenziali.

Parole chiave: giurisprudenza, cambiamento di giurisprudenza, responsabilità dello stato, danno anti-giuridico, errore giurisdizionale. 


\section{RESPONSABILIDADE DO ESTADO POR SIMPLES MUDANÇA DE JURISPRUDÊNCIA NO DIREITO COLOMBIANO}

\section{Resumo}

Este artigo analisa se a simples mudança de jurisprudência pode gerar responsabilidade patrimonial do Estado no direito colombiano. Com este proposito apresenta-se como na prática judiciária do Conselho de Estado e a Suprema Corte de Justiça mudaram sua jurisprudência, e o efeito que isso gera para as partes em litígio. Posteriormente serão descritos os elementos que estruturam a responsabilidade do Estado pela atividade da administração da justiça na Colômbia, especificamente pelo erro jurisdicional. Demonstrado que, em certos casos, é possível concluir, teoricamente, que a responsabilidade do Estado é gerada no direito colombiano pelas simples mudanças jurisprudenciais.

Palavras-chave: jurisprudência, mudanças jurisprudenciais, responsabilidade do Estado, dano antijuridico, erro jurisdicional. 


\section{INTRODUCCIÓN}

Aunque los artículos 228 y 230 de la Constitución Política de Colombia establecen la regla general de independencia y autonomía del poder judicial, en virtud de la cual los jueces en sus providencias sólo están sometidos al imperio de la ley, parece claro que la jurisprudencia tiene hoy "carácter obligatorio frente a la toma de futuras decisiones" (CConst, C-461/2013) con lo cual se pretende respetar principios constitucionales como la igualdad, la buena fe y la confianza legítima que garantizan la uniformidad en la interpretación y aplicación de la ley para preservar la seguridad jurídica y, con ella, la certeza que la comunidad tiene de que los jueces van a decidir los casos iguales de la misma forma (CConst, T-014/2009). ${ }^{1}$

De hecho, leyes como la 1395 de 2010 (artículo 115 aún vigente pese a que dicha ley fue derogada casi en su totalidad) y la 1437 de 2011 (artículos 10, 102, 256 y 269) contienen disposiciones orientadas a la aplicación uniforme de la jurisprudencia, la cual puede ser cambiada (CConst, SU-047/1999) si se cumple con las cargas de transparencia y argumentación suficiente que implican, en su orden, revelar la existencia de la doctrina que va a ser cambiada, y exponer razones de peso que venzan el criterio a modificar, lo que hace razonable variar la línea jurisprudencial (CConst, C-400/1998 y CConst, C-836 2001). ${ }^{2}$

El problema planteado en este trabajo consiste en determinar si los simples cambios de jurisprudencia, permitidos en la práctica judicial, pueden generar la responsabilidad patrimonial del Estado en el derecho colombiano. Con tal propósito se abordará, inicialmente, el fenómeno del cambio de jurisprudencia y sus efectos para las partes en litigio a partir de casos reales resueltos por el Consejo de Estado y la Corte Suprema de Justicia. Luego se hará una síntesis de los elementos que estructuran la responsabilidad patrimonial del Estado en Colombia por la actividad judicial, concretamente por el error jurisdiccional, dentro del marco definido en la Consti-

1 También CConst, T-766/2008, CConst, T-808/2007, CConst, T-589/2007, CConst, T-571/2007, CConst, T-731/2006, CConst, T-1130/2003, CConst, C-836/2001, entre otras.

2 Confrontar CConst, C-400/1998 y CConst, C-836/2001. Hasta la Corte Constitucional puede, según sus propias palabras, cambiar jurisprudencia en materia de control constitucional con "razones poderosas" que lo justifiquen, como cuando sobrevienen reformas constitucionales, cuando así lo demanda el carácter dinámico de la Constitución Política, o cuando resulta necesario realizar una nueva ponderación de valores o principios constitucionales. Véase CConst, C-259/2015 y CConst, C-073/2014. 
tución Política, la ley 270 de 1996 y los pronunciamientos judiciales de la Corte Constitucional y el Consejo de Estado. Finalmente, se determinará si en los cambios de jurisprudencia se presentan los elementos que estructuran la responsabilidad del Estado en Colombia.

Este artículo es de reflexión, de tal suerte que presenta resultados de investigación pero desde un punto de vista interpretativo y crítico del autor, producto del análisis de las distintas fuentes documentales consultadas: normativas, doctrinales y, en mayor medida, jurisprudenciales. Así, hubo revisión de sentencias del Consejo de Estado y de la Corte Suprema de Justicia en las que tales autoridades cambiaron jurisprudencia; como también fue objeto de estudio la jurisprudencia del Consejo de Estado y de la Corte Constitucional en torno a la responsabilidad patrimonial del Estado, especialmente la que se genera por la actividad jurisdiccional. Se empleó el método inductivo a partir de la descripción de dos casos concretos de cambio de jurisprudencia, uno resuelto por el Consejo de Estado y el otro por la Corte Suprema de Justicia, lo que permitió conocer los efectos de ese fenómeno y contrastarlos con las normas jurídicas colombianas. Lo anterior condujo a la conclusión, según la cual, eventualmente, el simple cambio de jurisprudencia puede generar la responsabilidad del Estado en el derecho colombiano.

\section{CAMBIO DE JURISPRUDENCIA}

Este artículo no pretende definir lo que es "jurisprudencia" ni su condición de fuente del derecho. ${ }^{3}$ Tampoco se propone resolver si es lo mismo que precedente o doctrina probable. ${ }^{4} \mathrm{Sin}$ embargo, para el propósito planteado interesa recordar que actualmente en Colombia, pese a que su sistema de derecho tiene la estructura y los fundamentos de un sistema de derecho continental, "las sentencias judiciales tienen el carácter de precedente"

3 Sobre el particular puede consultarse, entre otros: Clemente de Diego, F. (1925). La jurisprudencia como fuente del Derecho. Revista de Derecho Privado; Kocourek, A. (1932). Sources of law in The United States of North America an their Realtion to Each Other. American Bar Association Journal, 18(10); Puig, J. (1952). La jurisprudencia como fuente del derecho: interpretación creadora y arbitrio judicial. Barcelona: Bosch y Calvo, F. (1992). La jurisprudencia ¿Fuente del Derecho? Valladolid: Lex Nova.

4 Ley 169 de 1896: "Artículo 4․ Tres decisiones uniformes dadas por la Corte Suprema, como tribunal de casación, sobre un mismo punto de derecho, constituyen doctrina probable, y los jueces podrán aplicarla en casos análogos, lo cual no obsta para que la Corte varíe la doctrina en caso de que juzgue erróneas las decisiones anteriores". 
(Bernal, 2008), en tanto que "es una regla establecida acatar los precedentes anteriores donde los mismos puntos se someten nuevamente a litigio; para mantener la balanza de la justicia uniforme y constante, no susceptible de variar con la opinión de cada nuevo juez" (Blackstone, 1876, p. 47). ${ }^{5}$ De esa forma, las decisiones judiciales (que fijan el criterio o regla de derecho con que resolvieron un caso determinado) son una autoridad para los jueces en casos siguientes en los que se plantee el mismo asunto (Kocourek \& Koven, 1935); por lo que es vinculante para el mismo juez que dictó la decisión anterior como para los de menor jerarquía, cuyo desconocimiento injustificado le abre paso incluso a la acción de tutela (CConst, T-102/2014, entre otras). Con ello pretende respetarse el derecho a la igualdad, en tanto que los usuarios de la Administración de Justicia que se encuentren en similares supuestos reciben de esa forma el mismo trato.

En ese sentido, es necesario advertir que cuando en este artículo se haga referencia al término "jurisprudencia" se estará denotando las sentencias del Consejo de Estado y de la Corte Suprema de Justicia que fijan el criterio o regla de derecho con que resolvieron un caso determinado. Ello no quiere decir que las decisiones de otras autoridades judiciales no sean jurisprudencia, sino que las providencias de los órganos de cierre tienen un impacto diferente al que reflejan las de los jueces de jerarquía inferior. Así, por ejemplo, la ley 1437 de 2011 dispone la aplicación extensiva de la jurisprudencia del Consejo de Estado, no la de los jueces o tribunales administrativos, al reconocer así el carácter jerarquizado de nuestro sistema judicial, a tal punto, que la capacidad para crear reglas o subreglas en decisiones judiciales, que vincule a los jueces en casos posteriores, "solo puede provenir de los órganos de cierre en las distintas jurisdicciones como una consecuencia de las funciones a ellos asignada por la Constitución y en razón del carácter del Estado Colombiano como una República Unitaria" (CConst, C-631/2012). ${ }^{6}$

Por otra parte, por "cambio de jurisprudencia" se querrá indicar la modificación que de sus decisiones hacen tales cortes en casos similares a los decididos con anterioridad por ellas mismas. Es decir, tomar en un caso (caso 2) una decisión distinta a la de un asunto anterior (caso 1) pero similar,

\footnotetext{
5 "For it is an established rule to abide by former precedents, where the same points come again in litigation; as well to keep the scale of justice even and steady, and not liable to waver with every new judge's opinion" (traducción libre del autor).

6 Igual orientación en sentencia del CE, 2015-03358-00/2016, Sección Quinta.
} 
sin dejar de entender por similar la identidad de los supuestos fácticos que originaron el litigio, juzgados con las mismas normas jurídicas, en igual contexto histórico. Es un cambio en la decisión (un cambio de opinión) en un asunto que se resolvió de manera distinta a otro que guarda las similitudes señaladas. Si al comparar el caso 1 con el caso 2 se encuentra diferencia en alguno de los tres componentes descritos (hechos que generan la litis, normas aplicadas o escenario histórico), se lidiaría con conflictos distintos que, por lo tanto, merecen decisiones diferentes (distinguish anglosajón). No sería propiamente un cambio de jurisprudencia. Sobre el particular Bernal (2005) señala que la Corte Constitucional contempla la posibilidad "de que el juez pueda inaplicar la jurisprudencia a un determinado caso posterior, cuando considere que las diferencias relevantes que median entre este segundo caso y el primer caso en que se estableció la jurisprudencia exigen otorgar al segundo una solución diferente" (p. 222).

En ese sentido, la Corte Constitucional ha insistido en que la jurisprudencia no viene a ser una camisa de fuerza para el juez (CConst, T-292/2006), y que este puede apartarse de ella válidamente si justifica tal proceder como cuando: a) los hechos en el proceso en estudio son inaplicables al precedente concreto por ser distintos; b) hay un cambio en las disposiciones jurídicas aplicables o c) se considere que la decisión es contraria a los valores y principios en los que se estructura el ordenamiento jurídico, por un cambio social o histórico (CConst, C-836/2001). Sin embargo, se insiste, en tales circunstancias no habría en realidad cambio de jurisprudencia; el juez no estaría huyendo o apartándose de ella, sino que se estaría frente al mencionado distinguish, según se dijo ya.

Finalmente, este artículo no desarrolla el tema de la responsabilidad patrimonial del Estado por "aplicación retroactiva de cambio de jurisprudencia" (tratado en otro escrito), sino por "simple cambio de jurisprudencia". En la aplicación retroactiva el cambio de criterio jurisprudencial, que es desfavorable (por exigir por ejemplo un requisito para la presentación de la demanda que no existía cuando se demandó), se aplica a hechos que han tenido lugar antes del cambio, al quebrar la confianza legítima, la igualdad y la seguridad jurídica (Cuesta, 2015); mientras que lo que aquí se plantea es que en determinadas hipótesis las altas cortes niegan pretensiones (caso 1) al aplicar una jurisprudencia que posteriormente consideran errónea, por lo que la rectifican en los casos siguientes (caso 2 y posteriores) y conceden las pretensiones demandadas (cambio favorable), situación que viola el derecho a la igualdad en relación con el demandante en el caso 1; igualdad 
que sería restablecida si se aplicara retroactivamente el cambio jurisprudencial. A continuación se presentarán dos ejemplos para comprender mejor el alcance de este fenómeno.

\section{Prescripción de derechos laborales en el "Contrato realidad"}

En los contratos de prestación de servicios regidos por la ley 80 de 1993, el contratista no tiene en principio derecho al pago de prestaciones sociales; sin embargo, cuando ejecuta sus obligaciones contractuales bajo permanente subordinación, se abre paso el pago de tales prestaciones a su favor al completarse los elementos de una relación laboral (CConst, C-154/1997). En esos casos la Sección Segunda del Consejo de Estado, con fundamento en el artículo 41 del decreto 3135 de 1968, sostiene que la prescripción de los derechos laborales se interrumpía a partir del reclamo formulado por el contratista, por lo que este tenía derecho al pago del equivalente a las prestaciones sociales causadas dentro de los tres años anteriores al referido reclamo. Los derechos correspondientes al tiempo anterior a los mencionados tres años eran declarados prescritos (CE, 7765-05/2007, entre otras).

Sin embargo, el Consejo de Estado cambió expresamente su jurisprudencia y afirmó que el término de prescripción establecido en el artículo 41 del decreto 3135 de 1968 debe contarse desde el momento en que la sentencia a favor del contratista ordena el pago de la suma indemnizatoria, porque previo a la expedición de la sentencia que declara la primacía de la realidad laboral sobre la contractual no existe ningún derecho a favor del contratista. En esta nueva postura el Consejo de Estado sostiene que no "resulta razonable aplicar la prescripción trienal a la indemnización que se reconoce al contratista en la sentencia" (CE, 2152-06/2008). ${ }^{7}$

Este caso es un verdadero cambio de jurisprudencia pues no obedeció a la modificación de la realidad fáctica, normativa, ni histórica; cambio que trajo como efecto un tratamiento distinto a ciudadanos que se encontraban en el mismo supuesto fáctico (contrato realidad en contratos estatales de prestación de servicios) y jurídico (artículo 41 del decreto 3135 de 1968 sobre prescripción de derechos laborales); pues mientras a unos les estimó prescrito el derecho a reclamar sus prestaciones sociales (caso 1) a otros no (a partir del caso 2 en adelante).

7 Posición reiterada en CE, 2776-05/2008, CE, 3074-05/2009, CE, 1413-08/2010, CE, 1413-08/2011 y CE, 2013-01015-00/2013. 
Como el Consejo de Estado, la Corte Suprema de Justicia ha cambiado jurisprudencia. Vale la pena mencionar el que tuvo lugar en torno al tema de la aplicación retrospectiva de la ley 54 de 1990, por lo peculiar: el cambio de jurisprudencia obedeció a la modificación de la composición de la Sala.

Efectivamente, la posición consolidada de la Sala de Casación Civil de la Corte afirmaba que la ley 54 de 1990 no podía aplicarse al lapso de tiempo de las uniones maritales anterior a esa normativa, por impedirlo la rancia regla de irretroactividad de la ley, de ahí que el término de dos años que la ley mencionada establece para presumir la existencia de una sociedad patrimonial entre compañeros permanentes sólo debía computarse desde la fecha de su entrada en vigor, es decir, a partir del 31 de diciembre de 1990 (CSJ, 6984/2004). ${ }^{8}$ Dice la Corte sobre esta postura que "aparece como la más adecuada, porque sin duda alguna deja a salvo los principios de seguridad jurídica y justicia, que serían los que resultarían menguados de entenderse la retroactividad" (CSJ, 5883/2001).

Del criterio referido se desprende como efecto que a quienes, en el marco de una comunidad de vida permanente y singular, adquirieron bienes desde antes de la existencia de la ley 54, y demandaron ante la jurisdicción el reconocimiento de la existencia de la sociedad patrimonial de hecho, la Corte no les incluía en esta los bienes obtenidos en tiempo previo a dicha ley, ya que la Corporación entendía que ese mandato del legislador se aplicaba desde su entrada en vigencia, no antes; así, por ejemplo, la Corte, en sentencia del 9 de marzo de 2004, respaldó una decisión del respectivo tribunal de instancia en la que se declaró la existencia de la sociedad patrimonial desde el primero de enero de 1991 — primer día de inicio de vigencia de la ley 54 de 1990 — hasta agosto de 1994, cuando en realidad los compañeros habían convivido desde 1981.

Esa posición jurisprudencial vio su fin en octubre de 2005 a causa de un cambio de composición de la Sala de Casación Civil de la Corte. Ciertamente, si se observa la sentencia del 9 de marzo de 2004, la tesis jurisprudencial inicial era defendida por cuatro de los siete magistrados que componían la Sala: Pedro Octavio Munar Cadena, José Fernando Ramírez

8 Ese pensamiento se encuentra respaldado en otras sentencias de la CSJ, 6726/2003, CSJ, 6660/2002 y CSJ, 5883/2001. 
Gómez, Silvio Fernando Trejos Bueno y Cesar Julio Valencia Copete. Los tres magistrados restantes, disidentes ellos, eran los doctores Manuel Isidro Ardila Velásquez, Carlos Ignacio Jaramillo Jaramillo y Edgardo Villamil Portilla quienes efectivamente salvaron su voto. Para el año 2005 el doctor Ramírez Gómez, del grupo mayoritario, había dejado la Corporación, y se vinculó a ella el magistrado Jaime Alberto Arrubla Paucar, quien se sumó al hasta entonces grupo minoritario, lo que condujo a un cambio de jurisprudencia.

En la providencia de 2005, en la que se habla de un "novísimo cambio de postura", dijo la Corte que la ley 54 de 1990 sí rige las uniones maritales iniciadas con anterioridad a su promulgación, y que permanecieron durante su vigencia — no así a las que para ese momento habían terminado-, por eso, para los efectos de la conformación de la sociedad patrimonial entre compañeros permanentes, debía tenerse en cuenta la totalidad del tiempo que ellos convivieron, incluido el anterior al 31 de diciembre de 1990, lo cual no significa retroactividad de la ley sino su "retrospectividad" (CSJ, 0832-01/2005).

Dicho de otra forma, lo que hasta octubre de 2005 eran salvamentos de voto, se tornó desde esa fecha en la posición mayoritaria de la Sala por cuenta de su nueva conformación, posición que ha sido reiterada ${ }^{9}$ y que incluso, en palabras de la misma Corte, evita injusticias. Nótese lo siguiente: en su momento aseguró la Sala de Casación Civil que la tesis de la irretroactividad "aparece como la más adecuada, porque sin duda alguna deja a salvo los principios de seguridad jurídica y justicia" (CSJ, 5883/2001), mientras que hoy sostiene "que la retrospección o aplicación inmediata se entronca es con las cuestiones fácticas en curso y con las del porvenir, para "evitar que se perpetúen injusticias sociales"' (CSJ, 766223184001200500196-01/2010) (la cursiva es del original).

Como efecto de esa nueva postura jurisprudencial puede señalarse que fueron tratadas en forma desigual personas que se encontraban en el mismo supuesto fáctico y jurídico (hechos relevantes y normas aplicadas), así como en igual contexto histórico: a las parejas que acudieron a la jurisdicción antes de octubre 28 de 2005 (fecha del cambio) en busca del reconocimiento de la existencia de sociedades patrimoniales derivadas de uniones maritales de hecho, la Corte les dejó por fuera el tiempo convivido anterior

9 Confrontar, entre otras, CSJ, 4700131030032005-00611-01/2010 y CSJ, 7662231840012005-00196$01 / 2010$. 
a la vigencia de la ley 54 de 1990, y de contera, los bienes adquiridos en ese interregno; mientras que a las parejas que tuvieron la fortuna de que conflictos similares fueran resueltos después del cambio de composición de la Sala Civil de la Corte, ella les reconoció la existencia de dicha sociedad desde antes de la vigencia de la ley en mención, lo que implicó tener en cuenta para la sociedad marital los bienes obtenidos en ese lapso.

Con los ejemplos referidos, entre otros, ${ }^{10}$ se advierte que la Corte $\mathrm{Su}-$ prema de Justicia y el Consejo de Estado cambian su jurisprudencia y tienen ese proceder como ajustado al ordenamiento, pues se sostiene que de esa forma se evita la petrificación del orden legal y además, que las equivocaciones del pasado sean las equivocaciones del presente y del futuro (CConst, SU-047/1999), pero aun así, surge la siguiente inquietud: si las cortes quiebran la igualdad al denegar una pretensión a un ciudadano que se encuentra en determinado contexto fáctico, jurídico e histórico (caso 1), pero luego cambian su jurisprudencia (cambian de parecer) y a otro ciudadano que se encuentra en el mismo escenario del caso anterior le conceden sus pretensiones (caso 2), ¿debe el Estado responderle patrimonialmente al ciudadano del caso 1 por el cambio de parecer de las cortes en el caso 2 ?

\section{Elementos de la responsabilidad Patrimonial del Estado}

Antes de la Constitución de 1991 no existía en nuestro país disposición alguna que de manera expresa estableciera la responsabilidad del Estado (CConst, C-333/1996), la cual quedó estatuida en su artículo 90 por primera vez (Saavedra, 2002, p. 141 y Henao, 1996, p. 761), disposición que contiene la cláusula general de responsabilidad patrimonial del Estado (CE, 8118/1995).

10 Sobre corrección monetaria a favor de entidades aseguradoras que se subrogan en virtud del artículo 1096 del Código de Comercio véase CSJ, 0832-01/2005. En relación con la procedencia de la disminución punitiva establecida en el artículo 269 del Código Penal, cuando se trata del delito de extorsión cometido en vigencia de la ley 1121 de 2006, confrontar CSJ, 30800/2009, CSJ, 35767/2012 y CSJ, 37339/2012. En esta última se declara procedente la causal de revisión de cambio de jurisprudencia favorable. En torno a los efectos que debe surtir la declaratoria de inexequibilidad de una disposición en materia de seguridad social, que la Corte Constitucional declaró inexequible, pero sobre cuyo pronunciamiento de constitucionalidad no estableció efectos retroactivos, revisar CSJ, 42540/2012 y CSJ, 45312/2014. Sobre la clase de acto administrativo que constituyen las decisiones de la administración pública que clasifican arancelariamente una mercancía examinar CE, 15206/2006 y CE, 16090/2011. 
Del inciso primero de la disposición en cita ${ }^{11}$ se puede concluir que los elementos de la responsabilidad patrimonial del Estado en Colombia son: el daño antijurídico e imputabilidad de ese daño a la acción u omisión de un agente estatal, en armonía con lo expresado por la jurisprudencia (CE, $30623 / 2015),{ }^{12}$ que se describen en seguida.

\section{Daño antijurídico}

Según lo afirma el profesor Juan Carlos Henao (1998), el daño es "la aminoración patrimonial sufrida por la víctima" que debe tener la característica de personal, es decir, sufrido por quien reclama su reparación, y de cierto (pp. 84, 88 y 129), esto es, determinado o determinable (CE, 9004/2014). Ahora bien, ese daño se vuelve antijurídico cuando además de carecer de título jurídico válido excede las cargas que debe soportar el individuo por el hecho de vivir en sociedad, requisitos que son concurrentes de conformidad con lo discutido en la Asamblea Nacional Constituyente cuando se redactaba el artículo 90 de la Constitución Política (Asamblea Nacional Constituyente 1991a y 1991b); o como lo ha definido la jurisprudencia, apoyándose en la doctrina: "un daño será antijurídico cuando la víctima del mismo no esté obligada por imperativo explícito del ordenamiento a soportar la lesión de un interés patrimonial garantizado por la norma jurídica" $(\mathrm{CE}$, 6515/1991). ${ }^{13}$ En otros términos, el daño es antijurídico si se constata que el ordenamiento jurídico no le ha impuesto a la víctima el deber de soportarlo (CE, 27842/2005). ${ }^{14} \mathrm{Y}$ no se tiene el deber de soportar el daño porque él es contrario a la Carta Política o a una norma legal, o "irrazonable" en clave de los derechos e intereses constitucionalmente reconocidos (CE, 29004/2014).

Por otro lado, con la responsabilidad patrimonial del Estado concebida sobre la noción de daño antijurídico, y según las ponencias presentadas

11 Constitución Política: "Artículo 90. El Estado responderá patrimonialmente por los daños antijurídicos que le sean imputables, causados por la acción o la omisión de las autoridades públicas.

En el evento de ser condenado el Estado a la reparación patrimonial de uno de tales daños, que haya sido consecuencia de la conducta dolosa o gravemente culposa de un agente suyo, aquél deberá repetir contra éste".

12 También CE, 30623/2015, CE, 28439/2015, CE, 29764/2013, CE, 30424/2013, CE, 24392/2012, CE, 21515/2012, CE, 22163/2012, CE, 20097/2011, CE, 14405/2004, CE, 8118/1995, CE, 6144/1993, CE, 8163/1993, CE, 7622/1993, CConst, C-333/1996 y CConst, C-038/2006.

13 Véase CE, 8163/1993.

14 El mismo criterio en CE, 10867/2000, CE, 8163/1993 y CE, 6515/1991, entre otras. 
en la Asamblea Nacional Constituyente, se quiso abarcar formas de responsabilidad distintas a la de la falla del servicio público, como la responsabilidad por daño especial (Asamblea Nacional Constituyente, 1991a). ${ }^{15}$ Así, se desplaza el soporte de la responsabilidad administrativa del concepto subjetivo de la antijuridicidad de la acción del Estado al concepto objetivo de la antijuridicidad del daño producido por esa acción. Es decir, la responsabilidad se deriva del efecto de la acción administrativa — el daño que debe ser antijurídico - y no de la actuación del agente estatal que lo causa, por lo que es la posición de la víctima del daño la que interesa, mas no la conducta del victimario. Lo anterior implica que el Estado pueda responder patrimonialmente por daños antijurídicos provenientes de acciones u omisiones lícitas, así como por los generados por conductas ilícitas.

\section{Imputabilidad}

La imputabilidad es el otro elemento de la responsabilidad patrimonial del Estado que permite atribuir al órgano estatal el deber de indemnizar, y se logra a través de lo que la jurisprudencia ha denominado "títulos jurídicos de imputación": falla del servicio, riesgo excepcional y daño especial. Una especie de falla del servicio es el error jurisdiccional el cual tiene regulación propia en la ley 270 de 1996, cuyo estudio se aborda a continuación.

\section{Error jurisdiccional}

En el artículo 90 de la Constitución Política se encuentra contenida la responsabilidad patrimonial del Estado por la actividad de todas las ramas del poder público, como la judicial, cuya responsabilidad tiene además desarrollo legal en los artículos 65 y siguientes de la ley 270 de 1996 dentro del capítulo denominado "de la responsabilidad del Estado y de sus funcionarios y empleados judiciales". El inciso segundo de la disposición mencionada circunscribe la responsabilidad estatal por la acción u omisión de agentes judiciales a tres eventos: defectuoso funcionamiento de la Administración de Justicia, error jurisdiccional y privación injusta de la libertad. De ellos interesa, en vista de nuestro propósito, el concepto de "error jurisdiccional"

15 Ponencia del doctor Juan Carlos Esguerra Portocarrero ante la Comisión Primera, numeral $7^{\circ}$. Sin desconocer que el Consejo de Estado ya había reconocido el daño especial como título de imputación de responsabilidad. 
al que la Corte Constitucional y el Consejo de Estado en sus pronunciamientos se refieren indistintamente como "error judicial". Pese a ello, en adelante se hará referencia al concepto en estudio como "error jurisdiccional" por así haberlo denominado el legislador en el artículo 66 de la ley 270, que lo define como "aquel cometido por una autoridad investida de facultad jurisdiccional, en su carácter de tal, en el curso de un proceso, materializado a través de una providencia contraria a la ley".

De esa disposición se extrae como elementos del error jurisdiccional: que la autoridad que incurre en él goza de función jurisdiccional, entendida como la facultad de administrar justicia con el fin de declarar o reconocer el derecho mediante la aplicación de la Constitución y la ley (CConst, C-037/1996); que la autoridad investida de facultad jurisdiccional actúe como tal, es decir, ligada a la función pública de administrar justicia que desempeña, pues de lo contrario su actuación comprometería su responsabilidad personal (Dueñas, 2008, p. 79); que actúe en el curso de un proceso mediante una providencia, esto es, un auto o una sentencia, por medio de la cual se interpreta, se declara o se hace efectivo el derecho subjetivo (CE, 17507/2010); que la providencia dictada sea contraria a la ley, o sea, que contenga una equivocación que surge al adecuar los hechos del caso a las normas jurídicas aplicables, de la falta de aplicación de la norma que corresponde o de la indebida aplicación de la misma; o al apreciar erróneamente las pruebas en las cuales se fundamenta la providencia. También encaja en la idea de providencia contraria a la ley, la que quebranta la Constitución (CE, 24841/2013) ${ }_{1}^{16}$ por la fuerza normativa de la misma que vincula a todas las autoridades y a los particulares.

No sobra advertir que el que la providencia deba ser contraria a la ley, para que se presente el error jurisdiccional, no quiere decir que la contradicción deba ser grosera o arbitraria como lo estimó la Corte Constitucional al afirmar que el error en mención debe constituir una vía de hecho (CConst, C-037/1996), postura que ha sido rechazada por el Consejo de Estado pues, según esta corporación, la conducta subjetiva del agente no es condición necesaria para que exista el error jurisdiccional cuya existencia debe determinarse por la contrariedad de la providencia judicial enjuiciada, con el ordenamiento jurídico (CE, 37123/2015). ${ }^{17}$

16 También CE, 13258/1997.

17 Confrontar CE, 29085/2015. 
Por su parte, el artículo 67 de la ley 270 de 1996 indica como presupuesto del error jurisdiccional el ejercicio de los recursos procedentes contra la providencia judicial que contiene el error, lo cual da la posibilidad al interesado de solicitar al órgano judicial que lo corrija, de lo contrario, el perjuicio sería ocasionado por negligencia, y constituiría culpa exclusiva de la víctima que excluye la responsabilidad del Estado, tal como lo prevé el artículo 70 de la ley 270 de 1996 (CE, 17507/2010). ${ }^{18}$ Lo anterior implica entonces que la providencia judicial errónea se encuentre en firme, ya que "aun cuando una decisión judicial resulte equivocada, sí ésta aún puede ser revocada o modificada, el daño no resultaría cierto, pues el error no produciría efectos jurídicos y, además, podría superarse con la intervención del superior funcional" (CE, 14837/2006).

Finalmente, al decir de la Corte Constitucional, las altas corporaciones del país no pueden generar errores jurisdiccionales por ninguna razón (CConst, C-037/1996), tesis que no sólo riñe con el querer del Constituyente, que fue claramente estatuir la responsabilidad patrimonial del Estado por los daños antijurídicos que le sean imputables por la acción o la omisión de las autoridades públicas - y las altas cortes poseen, sin duda, esa condición—, sino también con la tesis del Consejo de Estado, que es quien en definitiva juzga la responsabilidad del Estado en nuestro país, corporación judicial que estima que las altas cortes de justicia sí pueden comprometer la responsabilidad estatal por error jurisdiccional (CE, 13275/2002).

A continuación se determinará si el cambio de jurisprudencia, en los términos indicados antes, genera responsabilidad al Estado.

\section{RESPONSABILIDAD DEL ESTADO POR CAMBIO DE JURISPRUDENCIA}

Tal como se expresó, el cambio de jurisprudencia es la modificación que de sus decisiones hacen las altas cortes en casos similares a los decididos con anterioridad por ellas mismas, en los que los hechos que dan lugar al litigio, las normas aplicables al mismo y el contexto histórico, son concordantes. No hay pues cambio de jurisprudencia cuando alguno de tales aspectos resulta distinto, dado que en ese caso se trataría de conflictos diferentes que reclaman decisiones disímiles. Es la decisión del juez la que varía; es un cambio de opinión de las altas cortes frente a conflictos similares que,

Véase CE, 13164/2001 y CE, 16594/2008. 
aunque ellas invoquen razones que soportan el cambio, no es coherente con el respeto a la igualdad que la Administración de Justicia debe a quienes se encuentran en la misma situación fáctica y jurídica, y en igual contexto histórico (artículo 13 de la Constitución Política).

El Consejo de Estado se opone a reconocer la responsabilidad del Estado por cambio de jurisprudencia con los argumentos según los cuales en tales casos la providencia que cambia de criterio jurisprudencial hace tránsito a cosa juzgada por lo que no se puede modificar; que ella no hace más que aplicar la tesis jurisprudencial vigente en ese momento, y que, además, se generaría inseguridad jurídica frente a las decisiones de los jueces ante la posibilidad de que sobre sentencias ejecutoriadas se reabra el debate judicial (sentencia del 18 de julio de 2002). ${ }^{19}$

La cosa juzgada no es en realidad un obstáculo para que se declare la responsabilidad del Estado por cambio de jurisprudencia como una especie de error jurisdiccional, dado que el régimen de responsabilidad se propone garantizar la reparación integral de la víctima, “... sin que para ello tenga que modificarse la providencia judicial que contiene el error, razón por la cual la fuerza de cosa juzgada que a la decisión judicial en firme caracteriza, se mantiene incólume" (CE, 16594/2008). ${ }^{20}$

$\mathrm{El}$ análisis realizado a las fuentes consultadas indica que se presenta un error jurisdiccional por cambio de jurisprudencia que genera la responsabilidad patrimonial del Estado cuando ese fenómeno (el cambio), produce tratos desiguales, ocasiona daños antijurídicos, por ejemplo, en la modalidad de lucro cesante por la no obtención de las pretensiones por parte de un ciudadano a quien una alta corte se las negó en el caso 1, que por otro lado sí fueron concedidas a otros ciudadanos en casos posteriores, similares en los hechos, normas aplicables y contexto histórico; concesión que resulta de una rectificación jurisprudencial, lo que revela que el criterio empleado por las cortes para negar las pretensiones en el caso 1 no era acertado, de lo contrario, no lo hubieran rectificado. Lo dicho hace posible aclarar que aunque el sistema permita cambiar la jurisprudencia no es contradictorio sostener que ello constituya un error jurisdiccional, porque lo que se plantea es que el error mencionado se encuentra en la providencia que resolvió el

19 En igual sentido se pronunció recientemente un juzgado (Juzgado Tercero Administrativo Oral de Descongestión del Circuito de Quibdó, 31 de octubre de 2014). Al momento de redactar este artículo el recurso de apelación presentado contra esa providencia no ha sido resuelto.

Véase también CE, 14837/2006. 
caso 1, no en la del caso 2 en donde surge el cambio; error que se pone de manifiesto cuando la corte de cierre lo "rectifica" en el caso 2 al cambiar su jurisprudencia.

El daño es antijurídico porque carece de título jurídico válido y excede además el conjunto de las cargas que normalmente debe soportar el individuo en su vida social, según los requisitos expuestos en la Asamblea Nacional Constituyente al discutirse sobre los elementos de la responsabilidad del Estado, como se indicó antes. En efecto, carece de título jurídico válido porque no existe en el ordenamiento jurídico una disposición que legitime el detrimento que se causa a un ciudadano con la aplicación de un criterio jurisprudencial que posteriormente es considerado erróneo por las mismas altas cortes — de ahí su cambio_- de quienes la sociedad espera mayor acierto en sus providencias. Expresado en otros términos, los ciudadanos del caso 1 no tendrían el deber jurídico de soportar el daño - lo cual lo torna antijurídico - que causa la aplicación de una tesis jurisprudencial equivocada. Ese daño es imputable al Estado a través del error jurisdiccional, que es el cometido por una autoridad investida de facultad jurisdiccional, en su carácter de tal, en el curso de un proceso, materializado a través de una providencia contraria a la ley, tal como lo define el artículo 66 de la ley 270 de 1996; y no hay duda de que la Corte Suprema de Justicia y el Consejo de Estado son autoridades públicas que actúan investidas de facultad jurisdiccional cuando profieren una providencia que no sólo es contraria a la ley, sino también a la Carta y a distintos instrumentos internacionales.

Ciertamente, los cambios de jurisprudencia frente a conflictos similares no armonizan con los artículos 24 de la Convención Americana sobre Derechos Humanos "Pacto de San José de Costa Rica" aprobado por la ley 16 de 1972; ${ }^{21}$ 14-1 y 26 del Pacto Internacional de Derechos Civiles y Políticos, aprobado por la 74 de $1968^{22}$ y 13, 29 y 229 de la Constitución Política, disposiciones que consagran los derechos a la tutela judicial efectiva, a la igualdad y al acceso a la Administración de Justicia, como garantías

21 "Artículo 24. Igualdad ante la Ley. Todas las personas son iguales ante la ley. En consecuencia, tienen derecho, sin discriminación, a igual protección de la ley".

22 "Artículo 14. 1. Todas las personas son iguales ante los tribunales y cortes de justicia. [...]".

“Artículo 26. Todas las personas son iguales ante la ley y tienen derecho sin discriminación a igual protección de la ley. A este respecto, la ley prohibirá toda discriminación y garantizará a todas las personas protección igual y efectiva contra cualquier discriminación por motivos de raza, color, sexo, idioma, religión, opiniones políticas o de cualquier índole, origen nacional o social, posición económica, nacimiento o cualquier otra condición social". 
de las cuales goza toda persona para impedir, entre otros procederes, tratos discriminatorios a quienes se encuentran en similares situaciones de hecho y de derecho. Ello, porque la igualdad implica que la aplicación de la ley a los ciudadanos se lleve a cabo de manera uniforme, salvo que medie una justificación objetiva y razonable que permita un trato distinto; y no parece una justificación suficiente el aplicar un criterio jurisprudencial —con el que se deniegan las pretensiones judiciales de un ciudadano- que luego es cambiado por otro con el que se resuelven pretensiones a favor de otros ciudadanos en procesos judiciales similares, porque aquel criterio ya no "resulta razonable", como lo dijo el Consejo de Estado cuando cambió de parecer en el tema de contrato realidad citado al inicio del artículo (CE, 2152-06/2008), o que es modificado para "evitar que se perpetúen injusticias sociales", como lo aseguró la Sala de Casación Civil cuando varió su posición jurisprudencial en torno a la aplicación en el tiempo de la ley 54 de 1990 (CSJ, C-7662231840012005-00196-01/2010).

El ciudadano común, ajeno a las complicaciones jurídicas, no comprende por qué a él le deniegan sus pretensiones, mientras que a otro, en su misma situación, le fueron concedidas, tal como lo sostuvo la Corte Constitucional en el caso de un pensionado a quien la Corte Suprema de Justicia trató en forma desigual porque a otros les permitió actualizar su pensión, pero a aquel no: "De manera que no puede entender por qué, estando en las mismas circunstancias que las suyas, otro pensionado, en tanto él no, podrá mantener el poder adquisitivo de su pensión" (CConst, T-441/2007).

Entonces, aunque no hay evidencia empírica, teóricamente es posible concluir que si las altas cortes cambian su jurisprudencia y ocasionan con tal proceder daños antijurídicos, se genera responsabilidad patrimonial del Estado por error jurisdiccional al reunirse los elementos que lo configuran de conformidad con los artículos 90 de la Constitución Política y 66 de la ley 270 de 1996.

Un vocablo contenido en el artículo $4^{\circ}$ de la ley 169 de 1896, disposición declarada exequible por la Corte Constitucional por la sentencia C-836 de 2001, parece apoyar la conclusión precedente al disponer que: "Tres decisiones uniformes dadas por la Corte Suprema, como tribunal de casación, sobre un mismo punto de derecho, constituyen doctrina probable, y los jueces podrán aplicarla en casos análogos, lo cual no obsta para que la Corte varíe la doctrina en caso de que juzgue erróneas las decisiones anteriores" (el subrayado no es del original). La Corte Constitucional explicó en la sentencia C-836 de 2001 que el término "erróneo" puede entenderse 
de tres maneras diferentes, dando lugar a cambios de jurisprudencia por razones distintas: en primer lugar, cuando una situación social determinada no responda adecuadamente al cambio social posterior (que, contrario a lo que piensa la Corte, no es realmente un cambio de jurisprudencia por lo explicado antes); en segundo lugar, cuando se considera que la jurisprudencia es errónea por ser contraria a los valores, objetivos, principios y derechos en los que se fundamenta el ordenamiento jurídico, en cuyo caso el cambio jurisprudencial impide prolongar en el tiempo las injusticias del pasado; y en tercer lugar, por cambios en el ordenamiento jurídico (tampoco sería cambio de jurisprudencia).

La sentencia referida añade que "Debe entenderse entonces que el error judicial al que hace referencia la norma demandada [el artículo 4 de la ley 169 de 1896] justifica el cambio de jurisprudencia en los términos expresados, pero no constituye una facultad del juez para desechar la doctrina de la Corte Suprema de Justicia sin un fundamento explícito suficiente" (el subrayado no es del original). Y aunque se entiende que cuando la Corte en la sentencia citada habla de "error judicial" no se refiere al error jurisdiccional como título de imputación de responsabilidad al Estado, es claro que el cambio de jurisprudencia supone que el criterio jurisprudencial reemplazado es "erróneo" por contrariar los valores, principios y derechos en los que se fundamenta el ordenamiento jurídico, lo que encaja en la idea de "providencia contraria a la ley" contenida en el artículo 66 de la ley 270 de 1996 que define el error jurisdiccional.

\section{CONCLUSIONES}

En un Estado Social de Derecho, en el que se tiene como centro al ser humano, no tendría aceptación que las autoridades ocasionaran daños antijurídicos y no fueran reparados. Así lo ha expresado el Consejo de Estado citando a la Corte Constitucional, para quien el daño antijurídico tiene fundamento en principios constitucionales como la solidaridad y la igualdad, y en la garantía de protección del patrimonio de los ciudadanos, prevista en los artículos 2 y 58 de la Carta. Es por eso que "un Estado Social de Derecho y solidario y respetuoso de la dignidad de la persona humana, no puede causar daños antijurídicos y no indemnizarlos" (CE, 29004/2014).

Cuando el cambio de jurisprudencia genera daños antijurídicos, ellos son imputables jurídicamente al Estado como error jurisdiccional, en tanto 
se presentan los elementos que configuran ese título de imputación. A pesar de ello el Consejo de Estado se rehúsa a aceptarlo, quizás por la vanidad que impide usualmente a los seres humanos reconocer que nos equivocamos; tal vez por el efecto que ello generaría sobre los distintos fallos en los que ha cambiado de jurisprudencia (no pocos en verdad); acaso por la eventual responsabilidad que por vía de repetición le llegare a caber a sus miembros, lo cual es poco probable ya que para la prosperidad de la repetición es requisito indeficiente que el agente que dio lugar al pago de la condena haya actuado con dolo o culpa grave, según lo dispuesto en el inciso segundo del artículo 90 de la Constitución Política, y en verdad, creemos que ese aspecto subjetivo no se presenta en el cambio de jurisprudencia, fenómeno que obedece más a un cambio de parecer o, como lo llama el profesor Diego López Medina (2006), a un "arrepentimiento" (p. 209).

Con todo, debe reconocerse que aceptar la responsabilidad del Estado por cambio de jurisprudencia y, por ende, que hay derecho a la reparación de los perjuicios ocasionados a quienes se les aplicó un criterio jurisprudencial no acertado — que por ello después es cambiado - resulta problemático, pues podría argüirse al mismo tiempo que a la contraparte de aquellos se les viola el derecho a la igualdad y eventualmente tendrían derecho a ser también indemnizados, lo cual deviene contradictorio. Se explica: en el ejemplo referido antes sobre la prescripción de derechos laborales de contratistas del Estado (contrato realidad), en el caso 1 la entidad pública resultó favorecida con la aplicación de dicha prescripción, pues el contratista no podía ya reclamarle el pago de las prestaciones sociales. Al presentarse el cambio de jurisprudencia (caso 2) la entidad pública demandada debe pagar las prestaciones sociales al contratista cuyo derecho, en el caso 1, la jurisprudencia estimó prescrito, por lo que las entidades públicas podrían también sostener que el cambio de jurisprudencia que se presenta en el caso 2 implica para ellas un trato desigual.

Por ello, parece más adecuado resolver a favor de la parte más débil, esto es, de los ciudadanos que se enfrentan en un litigio a las entidades públicas, lo que en verdad no resuelve el problema cuando demandante y demandado son particulares, pues en esos casos no siempre se advierte con facilidad cuál de los contendientes es más débil que el otro, como en el ejemplo jurisprudencial sobre aplicación en el tiempo de la ley 54 de 1990. Aquí la posible respuesta sería aceptar resignadamente que el criterio jurisprudencial nuevo (el del caso 2) es el correcto, lo que tampoco es garantía de acierto porque la experiencia ha demostrado que las altas cortes después 
de considerar incorrecta una tesis jurisprudencial la cambian por otra, pero más tarde la retoman. ${ }^{23}$

Lo dicho hasta aquí deja algunas respuestas, pero también inquietudes por la dificultad que el tema ofrece. Ello exige de las cortes de cierre sumo cuidado al momento de administrar justicia, y una seria reflexión sobre el sistema de fuentes del derecho: ¿nos quedamos con la ley y nos sujetamos a ella exegéticamente? ¿Nos apartamos de la frialdad del texto legal y acogemos la calidez de la interpretación jurisprudencial? ¿Habrá un término medio?

\section{REFERENCIAS}

Asamblea Nacional Constituyente (1991a). Gaceta Constitucional 56. Bogotá: República de Colombia.

Asamblea Nacional Constituyente (1991b). Gaceta Constitucional 77. Bogotá: República de Colombia.

Bernal, C. (2005). El derecho de los derechos. Bogotá: Universidad Externado de Colombia.

Bernal, C. (2008). El precedente en Colombia. Revista Derecho del Estado. Bogotá: Universidad Externado de Colombia, 21, 80-94.

Blackstone, W. (1876). The Commentaries of the Law of England. Vol. I of the Rights of Persons. Londres: William Clowes and Sons.

Congreso de la República de Colombia (1896). Ley 169 de 1896, sobre reformas judiciales. Bogotá: República de Colombia.

Congreso de la República de Colombia (1968). Ley 74 de 1968, por la cual se aprueban los "Pactos Internacionales de Derechos Económicos, Sociales y Culturales, de Derechos Civiles y Políticos, así como el Protocolo Facultativo de este último, aprobados por la Asamblea General de las Naciones Unidas en votación unánime, en Nueva York, el 16 de diciembre de 1966”. Bogotá: República de Colombia.

23 Verbigracia, la Sala de Casación Civil de la Corte Suprema de Justicia cambió su jurisprudencia en relación con los litigios por perjuicios ocasionados en los que tanto víctima como victimario realizaban actividades consideradas peligrosas. La tesis inicial (caso1), vetusta por lo demás, señalaba que en tales casos debía acudirse al concepto de culpa presunta, posición que fue abandonada en la sentencia del 24 de agosto de 2009, en la que sostuvo que lo correcto es aplicar la tesis del riesgo como una "concurrencia de actividades peligrosas" (caso 2); pero un año después le dio la espalda a ese pensamiento y retomó la tesis del caso 1 (CSJ, 4700131030032005-00611-01/2010). 
Congreso de la República de Colombia (1972). Ley 16 de 1972, por medio de la cual se aprueba la Convención Americana sobre Derechos Humanos "Pacto de San José de Costa Rica", firmado en San José, Costa Rica, el 22 de noviembre de 1969. Bogotá: República de Colombia.

Congreso de la República de Colombia (1996). Ley 270 de 1996, Estatutaria de la Administración de Justicia. Bogotá: República de Colombia.

Cuesta, A. A. (2015). Responsabilidad del Estado por aplicación retroactiva de cambios de jurisprudencia. Anuario de Responsabilidad Civil y del Estado, 2, 89-127.

Dueñas, R. (2008). La responsabilidad del Estado ante las acciones jurisdiccionales. Bogotá: Universidad del Rosario.

Henao, J. C. (1996). Presentación general de la responsabilidad extracontractual del Estado en Colombia. En II Jornadas Colombo Venezolanas de Derecho Público. Memorias, (pp. 731-803). Bogotá: Universidad Externado de Colombia.

Henao, J. C. (1998). El daño. Bogotá: Universidad Externado de Colombia.

Juzgado Tercero Administrativo Oral de Descongestión del Circuito de Quibdó (2014). Sentencia del 31 de octubre de 2014. Rad. N. ${ }^{\circ}$ 27003333002201400083-00.

Kocourek, A. \& Koven, H. (1935). Renovation of the Common Law Through Stare Decisis. Illinois Law Review, 29(8), 971-999.

López, D. E. (2006). El derecho de los jueces. Bogotá: Legis.

Saavedra, R. (2002) La responsabilidad extracontractual de la administración pública. Bogotá: Ediciones Jurídicas Gustavo Ibáñez.

\section{JURISPRUDENCIA}

\section{Consejo de Estado}

CE, 6515/1991.

CE, 7622/1993.

CE, 8163/1993.

CE, 6144/1993.

CE, 8118/1995.

CE, 13258/1997.

CE, 10867/2000. 
CE, 13164/2001.

CE, 13275/2002.

CE, 13398/2002.

CE, $14405 / 2004$.

CE, 27842/2005.

CE, 14837/2006.

CE, 15206/2006.

CE, 7765-05/2007.

CE, 2152-06/2008.

CE, 2776-05/2008.

CE, 16594/2008.

CE, 3074-05/2009.

CE, 1413-08/2010.

CE, 17507/2010.

CE, 1413-08/2011.

CE, 20097/2011.

CE, 16090/2011.

CE, 22163/2012.

CE, 21515/2012.

CE, 24392/2012.

CE, 24841/2013.

CE, 2013-01015-00/2013.

CE, 2013-01015-00/ 2013.

CE, 29764/2013.

CE, 29004/2014.

CE, 31056/2015.

CE, 30623/2015.

CE, 28439/2015.

CE, 29085/2015.

CE, 37123/2015.

CE, 2015-03358-00/2016.

Corte Constitucional

CConst, C-037/1996.

CConst, C-333/1996.

CConst, C-154/1997. 
CConst, C-400/1998.

CConst, SU-047/1999.

CConst, C-836/2001.

CConst, T-1130/2003.

CConst, C-038/2006.

CConst, T-292/2006.

CConst, T-731/2006.

CConst, T-441/2007.

CConst, T-571/2007.

CConst, T-589/2007.

CConst, T-808/2007.

CConst, T-766/2008.

CConst, T-014/2009.

CConst, C-631/2012.

CConst, C-461/2013.

CConst, C-073/2014.

CConst, T-102/2014.

CConst, C-259/2015.

\section{Corte Suprema de Justicia}

CSJ, 5883/2001, J. F. Ramírez.

CSJ, 6660/2002, J. Santos.

CSJ, 6726/2003, J. A. Castillo.

CSJ, 6984/2004, P. O. Munar.

CSJ, 0832-01/2005, C. I. Jaramillo.

CSJ, 08001-31-10-004-2000-00591-01/2005, C. I. Jaramillo.

CSJ, 30800/2009, J. L. Bustos.

CSJ, 11001-3103-038-2001-01054-01/2009, W. Namén.

CSJ, 4700131030032005-00611-01/2010, R. M. Díaz.

CSJ, 7662231840012005-00196-01/2010, J. A. Arrubla.

CSJ, 11001-31100212005-00997-01/2010, E. Villamil.

CSJ, 2540/2012, M. Burgos.

CSJ, 35767/2012, J. L. Bustos.

CSJ, 37339/2012, L. G. Salazar.

CSJ, 45312/2014, J. M. Burgos. 
